For a long time, especially in France, atropine has been employed more particularly as an adjunct to morphia, when the latter is needed to relieve pain \&c.; and Dr. BrownSéquard pointed out that the nausea and vomiting that sometimes attend the hypodermic use of morphia may be done away with by the addition of atropine to the solution. So we have for years had a fair indication of the applicability of atropine and morphia as a means of lessening the risk attending upon the administration of chloroform. Wishing to satisfy myself of the action of byoscine on the pneumogastric, I came to the Continent to avoid the anti-vivisection laws, and since being here the extreme kindness of the surgeons has enabled me to satisfy myself that the dangers of ether and chloroform can be greatly, if not entirely, removed by the injection of one centigramme of bydrochlorate of morphia and one milligramme of sulphate of atropia some twenty.five minutes previously to their administration in adults. Much less of the an asthetic is needed to produce anæsthesia, and the danger from its toxic effects is avoided. There is of ten no stage of excitement perceptible; salivary secretion is checked, an important point in ether inhalation, as swallowing and vomiting do not occur, but above all, the temporary suppression of the inhibitory action of the vagus over the heart removes the risk of its reflex arrest. Dr. Aubert, to whom is greatly due the credit of having practically introduced the mixed method of inducing anæsthesia, says that the atropine, as it is given beneath the skin, does not affect the pupil. In several of my cases, however, I have noticed a marked dilatation, and in those cases the increased rate of the cardiac pulsations has continued for several hours; yet generally, I think, the pupil may be taken as an aid in regulating the administration of the anæsthetic. For my part, I have found that by administering nitrous oxide gas immediately before the etber, either after Clover's method or that of Brain, the patient having been previously prepared as above described (the atropine and morphia injection), the most rapid surgical anæsthesia can be satisfactorily attained. Personally I am now in a great measure relieved from that painful anxiety attending the use of anæesthetics which an experience of over twenty years had not diminished. So far as I can discover, only one doubtful accident has occurred under the mixed method, and as many thousands of operations must now have been performed during its use, I think that we may consider its success as established. I am, Sirs, yours traly,

Sept. 19th, 1891.

G. CockburN SMrth.

\section{THE SUGGESTED HIGHER DENTAL DIPLOMA.} To the Editors of THE LANCET.

SIRs,-May I be permitted to say how perfectly I agree with Mr. Sewill, in the opinion he has expressed concerning the suggested higher dental diploma. Undoubtedly the present examination for the licence in Dental Surgery is a sufficient test of special knowledge, and any higher professional status to which the student may aspire can be fully realised in the attainment of a degree in Medicine, or in the acquisition of the Fellowship or Membership of the College of Surgeons. Of late years many of the best students of dental surgery have continued their course of study in the larger field of medicine, and have obtained one of these higher qualifications in addition to the special diploma. In the not far distant future I would venture to hops that few will be content with the mere licence to practice dentistry, and that all will desire to rank as members of the medical profession, although they may elect to confine their energies to a special subject.

I am, Sirs, yours faithfully,

Wimpole-street, W., Oct. 6th, 1891. Francis Fox.

\section{NORTHERN COUNTIES NOTES.}

\section{(From oUR OWN CoRRESPONDENT.)}

Opening of the University of Durham College of Medicine.

THE opening of the Durham College of Medicine at Newcastle took place on the 2nd inst. Dr. Heath, the president, took the chair, and Lord Londonderry presented the prizes and addressed the students. The mayor and sheriff of the city and many of our leading citizens attended, while there was a numerons audience of ladies and the general public.

Sunderland.

The foundation stone of the new isolation block and mortuary at the Sunderland Infirmarv was laid by the Bishop of Durham on the 28th ult. The isolation block consists of two wards and their annexes, for the purpose of isolating or observing doubtful cases. These two wards are as much disconnected as if they were in separate buildings. The mortuary block consists of a post-mortem room, with marble terazzo floor as well as marble slabs and sinks. Around the sides of the room are six receptacles for dead bodies, each having in front a spring shutter, 80 that the body desired to be seen by the friends of the deceased will be alone visible. The entire cost of the build. ings, which are most elaborate and complete, will be from $£ 2700$ to $£ 3000$, and they have been presented to the infirmary by Miss E. J. Forster. - The infant mortality at Sunderland last week was very high ; there were in all 83 deaths in the borough, showing a death-rate of 33 per 1000 . Of these, 49 were cases of children under the age of five years, or a rate of 19.5 per 1000 for infants alone. Diarrbces and affections of the respiratory organs would appear to be the principal factors in thus raising the infantile mortality.

South Dock North-Eastern Railway Ambulance Class.

Surgeon-Major Hutton, organising secretary of the St. John Ambulance Association, gave an address to this clase last week. There were representatives from the NorthEastern Marine Engineering Company, and from the work. men of the River Wear Commissioners, who intend forming classes during the coming winter. After the lecture a demonstration was given of first aid, which met with the lecturer's hearty approbation.

\section{Stockton.}

A Local Government inquiry has been held at Stockton last week, the corporation seeking to borrow $£ 10,000$ for a site, and for the erection thereon of an infectious diseases hospital, It was shown by the promoters that the borough has nearly 50,000 inhabitants. In past times they had been dependent upon Middlesbrough, but now the Middles brough officials refuse to receive patients from Stockton suffering from small-pox, scarlet fever, or typhoid fever. The medical officer of health, Mr. Clegg, alsogave evidence in support of the scheme, which is to be further reported upon. - The Stockton branch of the National Society for the Prevention of Cruelty to Children have taken premises which the Town Council have certified under the by.laws of the Act as a "place of safety" for children, and which is to be used as a refuge for children who ought to be removed from undesirable surroundings, but for whom the workhouse or the police station is not a desirable shelter.

\section{Cumberland.}

Miss Thomason Nelson, late of Moor-row, Cumberland, has left, amongst other charitable bequests, $£ 1000$ to the Cumberland Infirmary, Carlisle, $£ 500$ to the Cumberland. and Westmoreland Convalescent Institntion at Silloth, and $£ 500$ to the Border Counties Home for Incurables, Carlisle, all free of legacy duty.

\section{Mr. Gladstone's Visit to Newcastle.}

Mr. Gladstone arrived in Newcastle on Thursday night, having come on the same day straight through froms Perth. He drove direct from the Central Station to the Newcastle Mansion-house, and during most of this carriage journey his head was uncovered. The next evening he addressed an immense meeting in the Tyne Theatre. His time until the next morning, when he again addressed a vast meeting, was well filled up receiving friends, deputations, and keeping up his correspondence. When he left the Central Station on Saturday, again bareheaded, he was apparently as well as when he arrived; his voice was strong and well heard nver all the buildings where he spoke. Occasionally, indeed, in some of his higher tones there was noticeable a slight breakdown. Of this he seemed to be immedi ately aware, as he had recourse to his well-known egg mixture, and with marked benefit. This slight break in tone is probably due to mere dryness produced by congestion of the fauces causing temporary dryness or ex haustion of the store of mucus in the tonsillar follicles The meetings were largely attended by members of the 